Revista Educação e Políticas em Debate - v. 8, n. 2, p. 221-232, mai./ago. 2019 - ISSN 2238-8346

\title{
O Plano Nacional de Educação e a formação continuada de professores(as) para a educação básica: análise e monitoramento acerca da Meta 16
}

\author{
The National Education Plan and continuing teacher training for basic education: analysis and \\ monitoring about Goal 16
}

Plan national d'éducation et formation continue des enseignants pour l'éducation de base: analyse et suivi de l'Objectif 16

\author{
Bruna Werner ${ }^{1}$ \\ Instituto Federal Catarinense - Campus Camboriú \\ Filomena Lucia Gossler Rodrigues da Silva ${ }^{2}$ \\ Instituto Federal Catarinense - Campus Camboriú \\ Andressa Graziele Brandt ${ }^{3}$ \\ Instituto Federal Catarinense - Campus Camboriú
}

\begin{abstract}
Resumo: No texto, objetivou-se apresentar uma análise da Meta 16 do PNE 2014/2024, acerca da formação continuada de professores(as) para a educação básica. Partiu-se do seguinte questionamento: quais ações são necessárias para a materialização das estratégias da Meta 16? O percurso metodológico, de caráter qualitativo, bibliográfico e documental, baseou-se na aproximação dos autores do campo. Entre os resultados identificou-se que, acerca do indicador 16A, o percentual de professores(as) com formação em nível de pósgraduação aumentou de 2010 a 2017, passando de 24,5\% para 36,2\%. Em relação ao indicador $16 \mathrm{~B}$, que diz respeito à proporção de professores que realizaram cursos de formação continuada no período de 2012 a 2017, o mesmo demonstra que houve um crescimento, passando de $29,4 \%$ para $35,1 \%$.
\end{abstract}

Palavras-chave: Plano Nacional de Educação. Lei $n^{\circ}$ 13.005/2014. Meta 16 do PNE. Formação de professores.

\begin{abstract}
The objective of the text was to present an analysis of Goal 16 of PNE2014/2024, about the continuous formation of teachers for Basic Education. The following question was asked: what actions are needed to materialize Goal 16 strategies? The methodological path, qualitative, bibliographic and documentary, was based on the approach of the authors of the field. Among the results, it was found that for indicator 16A, the percentage of teachers with postgraduate education increased from 2010 to 2017, from $24.5 \%$ to $36.2 \%$. Regarding indicator $16 \mathrm{~B}$, which refers to the proportion of teachers who
\end{abstract}

\footnotetext{
${ }^{1}$ Licenciada em Pedagogia pelo Instituto Federal Catarinense (IFC) - Campus Camboriú. E-mail eubrunawerner@gmail.com. ORCID:https://orcid.org/0000-0001-6536-8584. L Lattes: http://lattes.cnpq.br/0639812387499386.

${ }^{2}$ Doutora em Educação e Professora do Instituto Federal Catarinense (IFC) - Campus Camboriú. E-mail: filomena.silva@,ifc.edu.br. ORCID: https://orcid.org/0000-0002-8275-7714.

${ }^{3}$ Doutora em Educação, Professora e Supervisora Educacional do Instituto Federal Catarinense (IFC) - Campus Camboriú. E-mail: andressa.brandt@ifc.edu.br. ORCID: https://orcid.org/0000-0002-8176-1930. Lattes: http://lattes.cnpq.br/5766947022430917.
} 
took continuing education courses, from 2012 to 2017 , the same shows a growth, from $29.4 \%$ to $35.1 \%$.

Keywords: National Education Plan. Law No. 13.005 / 2014. PNE target 16. Teacher training.

Résumé: L'objectif du texte était de présenter une analyse de l'objectif 16 de PNE2014/2024, relatif à la formation continue des enseignants pour l'éducation de base. La question suivante a été posée: Quelles actions sont nécessaires pour concrétiser les stratégies de l'objectif 16? Le parcours méthodologique, qualitatif, bibliographique et documentaire, était basé sur la démarche des auteurs du domaine. Parmi les résultats, il a été constaté que pour l'indicateur $16 \mathrm{~A}$, le pourcentage d'enseignants titulaires d'un diplôme de troisième cycle avait augmenté de 2010 à 2017 , passant de $24,5 \%$ à $36,2 \%$. En ce qui concerne l'indicateur $16 \mathrm{~B}$, qui fait référence à la proportion d'enseignants ayant suivi des cours de formation continue, de 2012 à 2017 , il en va de même pour une croissance de $29,4 \%$ à $35,1 \%$.

Mots-clés: Plan national d'éducation. Loi $\mathrm{n}^{\circ} 13.005 /$ 2014. Cible PNE 16. Formation des enseignants.

\section{Introdução}

No presente texto, desenvolvemos a pesquisa bibliográfica e documental para apresentar a análise do monitoramento da Lei $\mathrm{n}^{\mathrm{o}}$ 13.005, de 24 de junho de 2014, especificamente de sua Meta 16.

Em suma, o Plano Nacional de Educação (PNE) tem como finalidade direcionar os investimentos e as estratégias de melhoria da qualidade da educação nacional e é resultado de um amplo processo de discussão e consulta a diferentes agentes públicos e sociais envolvidos com a educação. Da construção do PNE participaram: o Conselho Nacional de Secretários de Educação (Consed) e a União Nacional dos Dirigentes Municipais de Educação (Undime), que coordenam as secretarias estaduais e municipais de educação. Além disso, diferentes organizações acadêmicas, associações profissionais e representantes nacionais atuantes na área educacional também foram envolvidos nas discussões, garantindo assim a participação dos estados (BRASIL, 2014b).

O PNE vigente teve sua aprovação dada pela Lei $n^{\circ}$ 13.005/2014 e tem validade de 10 anos. Com ele, tanto a sociedade quanto os entes federativos passaram a contar com uma referência para a elaboração e a consecução de políticas públicas voltadas à educação. O PNE conta com 10 diretrizes, que congregam seus objetivos maiores, voltados à melhoria da educação, além de 20 metas, que definem os patamares educacionais a serem alcançados, bem 
como 254 estratégias, que compreendem os meios para que as políticas públicas sejam planejadas, visando ao alcance definitivo das metas e a consolidação das diretrizes. Dessa forma, cabe aos estados e aos municípios elaborar planos de trabalho específicos para alcançar os objetivos estabelecidos pelo PNE (BRASIL, 2014a).

Saviani (2010, p. 388) aponta que a origem da ideia de um plano de educação de abrangência nacional surgiu durante a década de 1930, com a publicação do Manifesto dos Pioneiros da Educação Nova, como “[ ...] uma exigência para que o Sistema Nacional de Educação mantenha permanentemente suas características próprias”. Outrossim, a Lei de Diretrizes e Bases da Educação (LDB), Lei nº 9.394, de 20 de dezembro de 1996, define como competência da União elaborar um Plano Nacional de Educação, juntamente com os Estados, o Distrito Federal e os Municípios. Dessa forma, cabe aos Estados e Municípios elaborar seus próprios planos de educação, a fim de definir as estratégias para que seja possível alcançar as metas propostas pelo PNE (BRASIL, 1996).

Souza e Menezes (2017, p. 3) destacam que os Planos Estaduais de Educação (PEE) são instrumentos de gestão de grande importância, cujo objetivo é integrar as metas do PNE, abrangendo as necessidades territoriais do Estado e prevendo “[ [...] a sua articulação às demandas municipais, a fim de que essas localidades possam adequar o planejamento nacional às suas particularidades”.

A Secretaria de Estado da Educação de Santa Catarina (SED/SC), em seu site oficial, justifica a relevância do PEE pelo fato de se tratar de um instrumento com força de lei e aponta que a sua construção se deu por meio de discussões nas escolas, conferências municipais, regionais e estaduais, pelo Conselho Estadual de Educação e pelo Fórum Estadual de Educação. Deste modo, o Plano Estadual de Educação de Santa Catarina:

[...] materializa propostas educacionais para a melhoria da qualidade da educação e, por consequência, contribuirá efetivamente para a construção de uma sociedade menos desigual. O Plano confere materialidade ao discurso de educação como direito de todos e responsabilidade do Estado, mediante a institucionalização do Sistema Estadual de Educação de Santa Catarina, que integra ações em regime de colaboração com a União e os Municípios. Deste modo, viabiliza a democratização do acesso, a qualificação da permanência do estudante na escola e a formação de cidadãos críticos, bem como, a valorização dos profissionais da educação. (SANTA CATARINA, 2015, p. 11).

Por sua vez, o Plano Municipal de Educação (PME) deve ser coerente com as estratégias e metas do Plano Nacional e do Plano Estadual de Educação. A fim de nortear os Municípios na construção de seus Planos Municipais, o Ministério da Educação (MEC) elaborou um caderno de orientações (BRASIL, 2014b), sob responsabilidade da Secretaria de 
Articulação com os Sistemas de Ensino (Sase). O documento aponta que o Plano Municipal de Educação é de todos os cidadãos do município, devendo abranger as necessidades educacionais de sua população. Não é, portanto, um documento da prefeitura ou dos dirigentes municipais de educação, mas sim um compromisso destes órgãos para com os cidadãos que ultrapassa mandatos. Este caderno de orientações traz também as etapas da construção do PME e algumas orientações técnicas para isso.

Vale mencionar que o PNE apresenta as 20 metas a serem cumpridas em seu período de vigência. As metas contemplam os três níveis da educação básica e dizem respeito à qualidade, ao acesso e ao investimento em educação, formação continuada dos professores e inclusão.

Neste trabalho, focalizaremos na Meta 16, que diz respeito à formação continuada dos professores, analisando os resultados do relatório de acompanhamento das metas do PNE e o $\mathrm{PEE} / \mathrm{SC}$, discutindo estes dados com a realidade educacional.

Tendo em vista o exposto, a seguir, apresentamos as análises referentes à Meta 16 do PNE 2014/2024.

\section{Formação continuada de professores para a educação básica}

Ao longo da história da Educação no Brasil, o campo da formação de professores teve e ainda tem papel de destaque nos avanços da qualidade da educação e na emancipação dos sujeitos. Um dos elementos da formação de professores em que ainda precisamos avançar diz respeito à formação continuada dos docentes. Conforme Libâneo (2013), a formação continuada consiste nas ações ocorridas dentro e fora da jornada de trabalho dos professores, abrangendo desde a participação na construção do projeto político-pedagógico da escola, as reuniões e grupos de estudo, até os congressos, cursos e palestras.

Conforme o autor, essa formação continuada “[...] se faz por meio do estudo, da reflexão, da discussão e da confrontação das experiências dos professores [ [...]”, sendo responsabilidade tanto da escola quanto do docente, na medida em que "[...] o compromisso com a profissão requer que ele tome para si a responsabilidade com a própria formação” (LIBÂNEO, 2013, p. 191). A formação continuada envolve os setores pedagógico, técnico e administrativo, sendo 
Além disso, Lima e Coimbra (2013) defendem que a formação continuada é de fundamental importância para eliminar ou minimizar alguma possível falha na formação inicial, capacitando o professor para enfrentar os desafios do cotidiano escolar.

Nesse viés, a Resolução ${ }^{\circ}$ 2, de $1^{\circ}$ de julho de 2015 (BRASIL, 2015a), que define as Diretrizes Curriculares Nacionais (DCN) para a formação inicial em nível superior e para a formação continuada, em seu parágrafo $3^{\circ}$, estabelece que a formação inicial e continuada dos professores da educação básica consiste em um processo complexo e dinâmico, que deve visar à melhoria permanente da qualidade social da educação, bem como à valorização profissional.

Segundo as DCNs (BRASIL, 2015a), a formação continuada tem como objetivo repensar o processo pedagógico, os saberes e os valores, abrangendo as dimensões coletivas, profissionais e organizacionais. Envolve, portanto,

[…] atividades de extensão, grupos de estudos, reuniões pedagógicas, cursos, programas e ações para além da formação mínima exigida ao exercício do magistério na educação básica, tendo como principal finalidade a reflexão sobre a prática educacional e a busca de aperfeiçoamento técnico, pedagógico, ético e político do profissional docente. (BRASIL, 2015a).

Assim sendo, a formação continuada prevê: atividades formativas organizadas pelas instituições de ensino; atividades ou cursos de atualização e/ou de extensão e aperfeiçoamento; cursos de especialização lato sensu; cursos de metrado acadêmico ou profissional; e cursos de doutorado.

\section{Análises acerca da Meta 16 do PNE-2014/2024}

O Instituto Nacional de Estudos e Pesquisas Educacionais Anísio Teixeira (Inep) elaborou um relatório com o objetivo de monitorar o cumprimento das metas do PNE (BRASIL, 2016) . Este relatório é publicado a cada dois anos, sendo o resultado de um longo processo de discussão, construção e aprimoramento dos indicadores, com o qual se busca abranger as perspectivas dos técnicos, especialistas, educadores e representantes de entidades governamentais e não governamentais que atuam na área da educação e estão envolvidos no monitoramento do PNE. No presente trabalho, utilizamos os dados do $2^{\circ}$ Relatório de Metas do PNE, referente ao biênio 2016-2018.

Nesse sentido, a Meta 16 do PNE 2014/2024 é definida nos seguintes termos:

Formar, em nível de pós-graduação, 50\% (cinquenta por cento) dos professores da educação básica, até o último ano de vigência deste PNE, e 
garantir a todos (as) os (as) profissionais da educação básica formação continuada em sua área de atuação, considerando as necessidades, demandas e contextualizações dos sistemas de ensino. (BRASIL, 2015b, p. 275).

Para alcançar essa meta, o PNE define como estratégias: a realização de um planejamento estratégico, a fim de identificar a demanda por formação continuada e promover a oferta por parte das instituições públicas de ensino superior; a consolidação de uma política nacional de formação de professores da educação básica que defina as diretrizes nacionais, as áreas prioritárias, as instituições que realizarão estas formações e os processos de certificação das atividades formativas; a expansão dos programas de composição de acervos de obras de cunho educativo e programas específicos de acesso a bens culturais, disponibilizando tais materiais aos professores da rede pública, de modo a favorecer a construção do conhecimento e a valorização da pesquisa; a ampliação e consolidação de um portal eletrônico que subsidie a atuação dos professores, disponibilizando de forma gratuita materiais didáticos e pedagógicos; a ampliação da oferta de bolsas de estudo para pós-graduação dos professores da educação básica; e o fortalecimento da formação dos professores por meio da implementação das ações do Plano Nacional do Livro e Leitura e da instituição de um programa nacional de recursos para acesso a bens culturais pelo magistério público.

Conforme o relatório, a Meta 16, foco deste trabalho, possui dois objetivos centrais, a saber: a formação em nível de pós-graduação de $50 \%$ dos professores da educação básica até o último ano de vigência do PNE; e garantir formação continuada a todos os profissionais da educação básica em suas áreas de atuação, considerando as necessidades, demandas e contextos dos sistemas de ensino (BRASIL, 2016).

A fim de monitorar esses objetivos, o Inep elaborou dois indicadores, calculados a partir das informações disponíveis no Censo da educação básica. O primeiro desses indicadores foi denominado Indicador 16A e diz respeito ao percentual de professores da educação básica com pós-graduação lato sensu ou stricto sensu. Já o segundo, Indicador 16B, abrange o percentual de professores que realizaram cursos de formação continuada. Para estes indicadores, o Inep utilizou os dados do Censo da educação básica: os da série histórica de 2008 a 2017 para o indicador 16A e os da série histórica de 2012 a 2017 para o indicador 16B.

No que se refere ao Indicador 16A, os dados do relatório mostram que o percentual de professores com formação em nível de pós-graduação aumentou de 2010 a 2017, passando de $24,5 \%$ para $36,2 \%$. Este percentual representa “[ [...] 812.949 docentes com formação em nível de pós-graduação em 2017, de um total de 2.244.128 professores” (BRASIL, 2014a, p. 
270). No entanto, o relatório alerta que, se for mantido esse ritmo de crescimento, não será possível atingir a meta em 2024.

Ainda quanto à formação em nível de pós-graduação, os dados mostram que 34,4\% dos professores da educação básica possuem titulação em nível de especialização, porém são quase imperceptíveis os crescimentos percentuais de professores com mestrado e doutorado, com $2,4 \%$ e $0,4 \%$, respectivamente. No que se refere ao crescimento deste indicador por regiões, o relatório aponta que as regiões Sul, com 55,5\%, e Centro-Oeste, com 40\%, apresentam os maiores percentuais de professores pós-graduados em relação às demais regiões do país, ao passo que as regiões Norte $(26,2 \%)$ e Nordeste e (31,5\%) detêm os menores percentuais de professores com pós-graduação, reflexo das desigualdades regionais do Brasil.

Outro dado interessante trazido pelo relatório, no que se refere ao Indicador 16A, diz respeito ao percentual de professores pós-graduados em cada uma das etapas de ensino. Os dados apontam que: 43,7\% são do ensino médio; 38,9\% são dos anos finais; 36,0\% são dos anos iniciais; e $29,6 \%$ são da educação infantil. A rede pública de ensino apresenta maiores percentuais de professores com pós-graduação que a rede privada, e a rede federal se destaca nestes percentuais, com 76,6\% dos professores atuantes com formações em nível de pós-graduação.

Já o Indicador 16B, que diz respeito à proporção de professores que realizaram cursos de formação continuada no período de 2012 a 2017, utiliza como unidade de análise apenas os professores em regência de classe. Para este indicador, são considerados os cursos de formação continuada em áreas das três etapas da educação básica; educação de jovens e adultos; educação especial; educação indígena; educação do campo; educação ambiental; educação em direitos humanos; gênero e diversidade sexual; direitos da criança e do adolescente; educação para as relações étnico-culturais; história e cultura afro-brasileira e africana; interculturalidade; entre outras áreas.

Segundo o relatório, houve um crescimento nos percentuais de professores que realizaram cursos de formação continuada em pelo menos uma das áreas especificadas, que passou de 29,4\% em 2012 para 35,1\% em 2017.

Em valores absolutos, em 2017, esse percentual corresponde a 787.042 professores (de um total de 2.244.128). Assim, para atingir a meta, mais de um milhão de professores teriam que realizar essa formação até o final do período do Plano. Considerando-se que o objetivo é abranger $100 \%$ dos profissionais da educação básica, e não apenas os professores, fica evidente a dificuldade para que a meta seja alcançada até 2024. (BRASIL, 2014a, p. 276). 
Novamente, a região Sul apresenta o maior percentual de professores que realizaram cursos de formação continuada, com 54,5\%. Já a região Sudeste apresentou o menor percentual entre as regiões, com $28,6 \%$, e a região Nordeste obteve crescimento, passando de 24,3\% em 2012 para 34,7\% em 2017. Outro dado relevante trazido pelo relatório é que as redes públicas foram as que mais promoveram formação continuada dos professores.

Analisamos também o PEE/SC, em sua Meta 16, buscando identificar como o Santa Catarina aborda a Meta e quais as estratégias para que esta seja alcançada. O Plano Estadual tem período de vigência de 2015 a 2024. Assim, a Meta 16 consiste em formar $75 \%$ dos professores em nível de pós-graduação até o último ano de vigência do Plano Estadual, garantindo que todos os profissionais da educação básica recebam formação continuada em suas áreas de atuação, “[...] considerando as necessidades, demandas e contextualização dos sistemas de ensino" (SANTA CATARINA, 2015, p. 132).

Assim sendo, para que seja possível alcançar esta Meta, o PEE/SC define as seguintes estratégias:

16.1 Consolidar política estadual de formação, em nível de pós-graduação, de professores da educação básica, definindo diretrizes estaduais, áreas prioritárias, instituições formadoras. 16.2 Realizar, em regime de colaboração, o planejamento estratégico para o dimensionamento da demanda por formação em cursos de pós-graduação, para fomentar a respectiva oferta por parte das instituições públicas e comunitárias de educação superior, de forma orgânica e articulada às políticas de formação do Estado e Municípios. 16.3 Consolidar programa definido em legislação, de afastamento remunerado dos professores, para cursar pós-graduação. 16.4 Possibilitar a mobilidade de docentes em cursos de pós-graduação, em âmbito nacional e internacional, com licença remunerada durante o período em que estiver cursando. 16.5 Ampliar e garantir a oferta de bolsas de estudo integral de pós-graduação dos professores e demais profissionais da educação básica. 16.6 Diagnosticar, consolidar e garantir políticas públicas que atendam efetivamente as demandas específicas de pós-graduação, em nível de especialização, mestrado e doutorado aos professores que lecionam nas escolas do campo, indígenas e quilombolas. 16.7 Garantir programas de formação de professores e Profissionais da Educação Básica e suas modalidades, a oferta de cursos de pós-graduação - lato sensu e stricto sensu vagas, acesso e condições de permanência nas instituições de ensino superior públicas e comunitárias (SANTA CATARINA, 2015, p. 132).

Desse modo, observamos que o $\mathrm{PEE} / \mathrm{SC}$ adequou suas metas e estratégias para o cumprimento do PNE, majorando, na Meta 16, o percentual de professores que deverão estar formados em nível de pós-graduação até 2024: de 50\% previstos no Plano Nacional, para $75 \%$ no Plano Estadual. 
Quanto às estratégias para que a Meta 16 seja alcançada, percebemos que o PNE as direciona para a formação continuada dos professores, enquanto o PEE/SC aborda aspectos relacionados à formação em nível de pós-graduação. Assim, é válido destacar a forma com que a formação continuada dos professores da educação básica é realizada no Estado atualmente, em específico na Rede Estadual de Educação: ocorre duas vezes por ano, nos meses de fevereiro e julho, com datas e temas definidos pela SED/SC. Dessa forma, as formações ocorrem na escola em que os professores atuam, por meio de palestras, vídeos ou web conferências, cabendo aos coordenadores pedagógicos a organização, enquanto os materiais são fornecidos pela Secretaria.

Neste sentido, Shiroma et al (2005), nos diz que se faz de suma importância o estudo aprofundado e análises acerca de que conceitos e argumentos são privilegiados e quais temas são intencionalmente suprimidos nos documentos acerca dos programas de formação continuada e permanente, pois esse processo nos faz compreender a lógica ou racionalidade que sustenta os documentos sobre o assunto.

Segundo a mesma autora et al (2005), essa tarefa de análise dos documentos, exige um olhar investigativo e analítico sobre os textos oficiais, legislações, relatórios e documentos, pois proporciona ler e ver o que eles dizem de forma explícita, mas também para captar o que eles não dizem, ou seja, o que está implícito nos mesmos.

Portanto, na medida em que os temas e datas destas formações são definidos previamente, fica claro que as especificidades de cada escola não são levadas em consideração, visto serem profissionais diferentes, com formações diferentes, além de alunos com realidades e necessidades distintas. Se estas formações continuadas são realizadas somente duas vezes por ano, dariam conta de suprir as necessidades dos professores durante todo o ano letivo? $\mathrm{O}$ que parece é que o objetivo do Estado de Santa Catarina é mostrar que, 'em tese', o segundo objetivo da Meta 16 está sendo alcançado, pois as formações continuadas são oferecidas aos professores.

No entanto, a qualidade e a forma com que essas formações vêm sendo ofertadas certamente não dão conta de proporcionar aos professores e comunidade uma formação sólida para enfrentar os desafios do cotidiano escolar.

\section{Considerações provisórias}

O PNE é um instrumento de fundamental importância para que a sociedade possa acompanhar o cumprimento e a elaboração das políticas públicas educacionais, cabendo aos Estados e Municípios elaborar seus Planos Estaduais e Municipais e traçar suas metas para 
que seja possível alcançar os objetivos do Plano Nacional, e em consequência oportunizar uma educação pública, como direito de todos, de qualidade social e principalmente socialmente referenciada.

Neste trabalho, analisamos o Plano Nacional de Educação e o Plano Estadual de Educação de Santa Catarina, focalizando as discussões na Meta 16, que diz respeito à formação continuada dos professores da educação básica para que possamos refletir e analisar sobre como se faz necessário, a realização de ações efetivas de formação dos professores desse país e destacamos que o proposto só será possível com o cumprimento dos percentuais de financiamento da educação deste país.

Os resultados apresentados no Relatório do $2^{\circ}$ Ciclo de Monitoramento das Metas do PNE, referente ao biênio 2016-2018, mostram que o percentual de professores com formação em nível de pós-graduação vem crescendo, passando de 24,5\% para 36,2\%. Mas, embora crescente, este nível é muito baixo para que a Meta possa ser alcançada em 2024, sendo necessário um crescimento médio de 2 pontos percentuais por ano, maior, portanto, do que o ritmo de crescimento atual. Por isso, destacamos que por meio da ampliação de recursos e financiamento da educação pública, criação de plano de cargos e carreiras dos profissionais da educação que valorizem e oportunizem a formação continuada dos mesmos, cumprimento do piso nacional de educação pelos estados e municípios, com ações de valorização profissional e salarial, ou seja, com políticas públicas educacionais e curriculares, teremos a possibilidade de cumprimento dos objetivos propostos pela Meta 16.

Destacamos, que se essas medidas propostas a cima, não forem executadas pelos governantes, caminhamos para a precarização da educação pública brasileira, o que trará perversas consequências para a formação dos estudantes das escolas e universidades públicas deste país.

Outro dado relevante é que a rede federal apresentou o maior percentual de professores com pós-graduação de toda a amostra. A proporção de professores que realizaram cursos de formação continuada no país também vem crescendo, sendo a região Sul do país a com o maior percentual de professores que disseram ter realizado formação continuada em suas áreas de atuação. Desta forma, os dados demonstram que com investimento financeiro em recursos humanos, estruturais e de materiais os índices de qualidade, de permanência e de êxito dos estudantes da educação básica ocorre de forma crescente, o que traz contributos para toda a sociedade brasileira.

Ao estabelecer uma comparação entre as estratégias para o cumprimento da Meta 16 no PEE/SC e a realidade educacional do estado, percebemos uma preocupação por parte do 
poder público em proporcionar formação continuada aos professores da rede pública de ensino, o que demonstra que Santa Catarina vem se esforçando para alcançar a Meta dos Planos Estadual e Nacional. Em suma, destacamos que a real efetivação de medidas de financiamento e valorização da formação continuada são de suma importância para o cumprimento do proposto pelos referidos planos.

Entretanto, a forma com que esta formação ocorre não considera as necessidades, demandas e contextos da educação básica, ou seja, um dos principais objetivos da Meta 16. Pois, as formações ocorrem apenas duas vezes ao ano, com temas definidos pela Secretaria de Estado da Educação, sem levar em consideração as especificidades de cada instituição, de seus alunos, professores e demais membros da comunidade pelos estados e municípios de escolar, tampouco dá conta de suprir as reais necessidades do corpo docente.

Por fim, mencionados os recentes cortes nos investimentos em educação no país, tanto na educação básica, como no ensino superior, atingindo assim a qualidade da formação dos professores de diferentes áreas e níveis de ensino, o que certamente acarretará sérias consequências à qualidade da educação ofertada e dificultará e/ou impossibilitará o cumprimento das Metas do PNE, seja no contexto nacional, estadual e municipal.

\section{Referências}

BRASIL. Lei no 9.394, de 20 de dezembro de 1996. Lei de Diretrizes e Bases da Educação Nacional. Diário Oficial da União: Brasília, DF, Seção 1, p. 27833, 23 dez. 1996. disponível em: https://bit.ly/2DkOpG4>. Acesso em: 2 maio 2019. https://doi.org/10.11606/d.7.2013.tde-10092013-151829

BRASIL. Lei n 13.005, 25 de junho de 2014. Aprova o Plano Nacional de Educação - PNE e dá outras providências. Diário Oficial da União: Brasília, DF, Edição Extra, Seção 1, p. 1, 26 jun. 2014a. Disponível em: <https://bit.ly/2XOoVqQ>. Acesso em: 2 maio 2019.

BRASIL. MINISTÉRIO DA EDUCAÇÃO. O Plano Municipal de Educação: caderno de orientações. Secretaria de Articulação com os Sistemas de Ensino. Brasília, 2014b.

BRASIL. MINISTÉRIO DA EDUCAÇÃO. CONSELHO NACIONAL DE EDUCAÇÃO. CONSElHO PLENO. Resolução $n^{\circ} 2$, de $1^{\circ}$ de julho de 2015. Define as Diretrizes Curriculares Nacionais para a formação inicial em nível superior (cursos de licenciatura, cursos de formação pedagógica para graduados e cursos de segunda licenciatura) e para a formação continuada. Diário Oficial da União: Brasília, DF, Seção 1, p. 8-12, 2 jul. 2015 a. Disponível em: <https://bit.ly/37F6axE>. Acesso em: 3 maio 2019. https://doi.org/10.21573/vol32no12016.65681

BRASIL. INSTITUTO NACIONAL DE ESTUDOS E PESQUISAS EDUCACIONAIS ANÍSIO TEIXEIRA. Plano Nacional de Educação PNE 2014-2024: Linha de Base. Brasília, DF: Inep, 2015b. https://doi.org/10.1590/s2176-6681/371614642 
BRASIL. INSTITUTO NACIONAL DE ESTUDOS E PESQUISAS EDUCACIONAIS ANÍSIO TEIXEIRA. Relatório do $2^{\circ}$ ciclo de monitoramento das metas do PNE biênio 2016 2018. Brasília, DF: Inep, 2016. Disponível em: <https://bit.ly/2sijrvL>. Acesso em: 29 abr. 2019. https://doi.org/10.1590/s2176-6681/371614642

LIBÂNEO, José Carlos. Organização e gestão da escola: teoria e prática. 6. ed. São Paulo: Heccus Editora, 2013. 304 p.

SANTA CATARINA. Plano Estadual de Educação: 2015-2024. Florianópolis: [s. n.], 2015.

SAVIANI, Demerval. Sistema Nacional de Educação articulado ao Plano Nacional de Educação. Revista Brasileira de Educação, Campinas, v. 44, n. 15, p. 380-412, maio 2010. Disponível em: <https://bit.ly/2rpJO2C>. Acesso em: 27 abr. 2019. https://doi.org/10.1590/s1413-24782010000200013

SHIROMA, Eneida Oto; CAMPOS, Roselane Fátima; GARCIA, Rosalba Maria Cardoso. Decifrar textos para compreender a política: subsídios teórico-metodológicos para análise de documentos. Perspectiva, Florianópolis, v. 23, n. 02, p. 427-446, jul./dez. 2005. Disponível em: <http://www.ced.ufsc.br/nucleos/nup/perspectiva.html>. Acesso em 29 abr. 2019.

SOUZA, Donaldo Bello de; MENEZES, Janaína Specht da Silva. Planos estaduais de educação: desafios às vinculações com outros instrumentos de gestão local da educação. Revista Brasileira de Educação, Rio de Janeiro, v. 22, n. 71, p. 1-23, jul. 2017. Disponível em: <https://bit.ly/2KXHxCz>. Acesso em: 27 abr. 2019. https://doi.org/10.1590/s1413-24782017227152 